\title{
Low Wages Prevalent In Direct Care and Child Care Workforce
}

\author{
KRISTIN SMITH AND REAGAN BAUGHMAN
}

$\mathrm{T}$

The large scale movement of women into the paid labor market has brought sweeping change to the structure of family life, affecting who cares for the elderly and children. Today, our society depends, in part, on the caring work of many paid professionals and, as the number of elderly and children grow as is predicted by demographers, our society will increasingly depend on these workers. This policy brief examines the economic well-being of workers in two low-wage, predominantly female care giving occupations plagued with high turnover-direct care workers (personal care assistants, home care aides, home health aides, and certified nursing assistants) and child care workers (preschool and nursery school teachers, center-based child care providers, and home-based family child care providers). High turnover in both the direct care and child care workforce contributes to lower quality care leading to unfavorable outcomes for the elderly and children. Although these paid caregivers are employed, hourly wages are low and many live in low-income families and lack health insurance. Furthermore, research shows that those who work in occupations involving care work face a wage penalty, that is they earn less than expected based on their job characteristics and qualifications. ${ }^{1}$

\section{Direct Care and Child Care: Fast Growing Occupations in the Nation}

As the baby boom cohort nears retirement age, the question of how to provide necessary health care and personal services to a growing elderly population has become an immediate policy problem facing the United States. By 2030,
Direct care workers provide the majority of paid

hands-on care, supervision, and emotional

support to millions of people with chronic illnesses

and disabilities. These paraprofessional workers

hold a variety of job titles, such as personal care

assistants, home care aides, home health aides, and

certified nursing assistants (CNAs). They work in

diverse settings, including private homes, adult day

centers, assisted living residences, hospitals, and

nursing homes. In their jobs they may:

- assist with personal care activities, such as bathing, dressing, toileting, and eating;

- provide comfort and companionship;

- shop, prepare meals, and clean the house;

- provide oversight, administer medications, and measure vital signs. ${ }^{2}$

Child care workers provide early care and education to millions of preschool-age children, and after-school care and enrichment to gradeschoolage children. They work in child care centers and in private homes, and include preschool teachers, nursery school teachers, family child care providers, early childhood teacher's assistants, nannies, and child care providers. 
it is projected that there will be about 70 million Americans aged 65 and older, more than twice their number in $2000 .^{3}$ As individuals age, their need for assistance with activities of daily living (ADLs) and long-term care increases. ${ }^{4}$ Currently, about 6 million people over the age of 65 require assistance to manage their everyday activities ${ }^{5}$ and about 2.6 million Americans worked as direct care workers in 2005.6 Between 2004 and 2014, direct care occupations are projected to be among the fastest-growing in the nation. ${ }^{7}$ In fact, the Bureau of Labor Statistics reports that between 1992 and 2005, home health aide was the fastest growing occupation closely followed by home care aide, highlighting the demand and preference for home-based care.

The demand for child care providers has also grown substantially over the last few decades as more women with children have entered the labor force, and as the number of children in America has grown. By 2030, it is projected that there will be 24 million young children, those four years old or younger, an increase of 26 percent from the number in $2000 .^{8}$ The growing number of children in need of nonparental care has fueled the growing number of child care workers. Between 1992 and 2005 the child care occupations grew by 66 percent. ${ }^{9}$ The child care workforce is projected to grow 38 percent between 2004 and 2014, a higher rate of growth than projected for the overall workforce (14 percent).

\section{Profile of Direct Care and Child Care Workers}

\section{Direct Care and Child Care Workers Predominantly Female}

In 2005, 2.7 million workers 19 or older were employed in direct care occupations, constituting 2 percent of the American workforce (see Table 1). Another 1.6 million were in child care occupations (roughly 1 percent of the total workforce).$^{10}$ Both of these occupations are predominantly female -89 percent of direct care workers and 97 percent of child care workers are women. ${ }^{11}$

Among female workers, 2.4 million (or 3 percent) are direct care workers and 1.5 million (or 2 percent) are child care workers. Direct care workers are increasingly working as home health aides, as more and more elderly Americans remain in their homes as they age, but still need assistance with activities of daily living. Forty-two percent of female direct care workers are home health aides and another 41 percent are nursing home aides (see Figure 1). The remaining 17 percent work in hospitals. According to the CPS, 12 percent of the child care workforce works in a home environment, and 88 percent work in a child care center.
Table 1. Direct Care and Child Care Workers, 2005

\begin{tabular}{lcccccc}
\hline & \multicolumn{2}{c}{ All Workers } & \multicolumn{2}{c}{ Direct Care Workers } & \multicolumn{2}{c}{ Child Care Workers } \\
\cline { 2 - 7 } & NUMBER & PERCENT & NUMBER & PERCENT & NUMBER & PERCENT \\
\hline All Workers & 149,326 & 100 & 2,673 & 2 & 1,561 & 1 \\
Female Workers & 69,557 & 47 & 2,389 & 89 & 1,510 & 97 \\
\hline
\end{tabular}

Source: 2006 March CPS

Numbers in thousands. Based on weighted data for workers 19 years and older.

\section{Direct Care Workers Disproportionately Minorities and Foreign Born}

Roughly half (49 percent) of female direct care workers are minorities, and black women disproportionately work as direct care workers (see Table 2). Just under one-third of female direct care workers are black, non-Hispanic-a proportion two times higher than that found in the child care workforce and the female workforce overall. Similarly, a higher proportion of direct care workers are foreign born (20 percent) compared with child care workers (16 percent) and all female workers (13 percent). One difference across industry and occupation within the direct care workforce is that home health aides are proportionately less likely to be black, non-Hispanic and proportionally more likely to be Hispanic than the direct care workers employed in hospital or nursing home settings. The child care workforce more closely mirrors the overall female workforce with regard to race and ethnicity, although child care workers are slightly more likely to be Hispanic than all female workers.

Child care workers are more likely to be married than direct care workers ( 49 percent and 38 percent, respectively), and are more likely to have children. About one quarter of

Figure 1. Distribution of Female Direct Care and Child Care Workers by Occupation Group, 2005

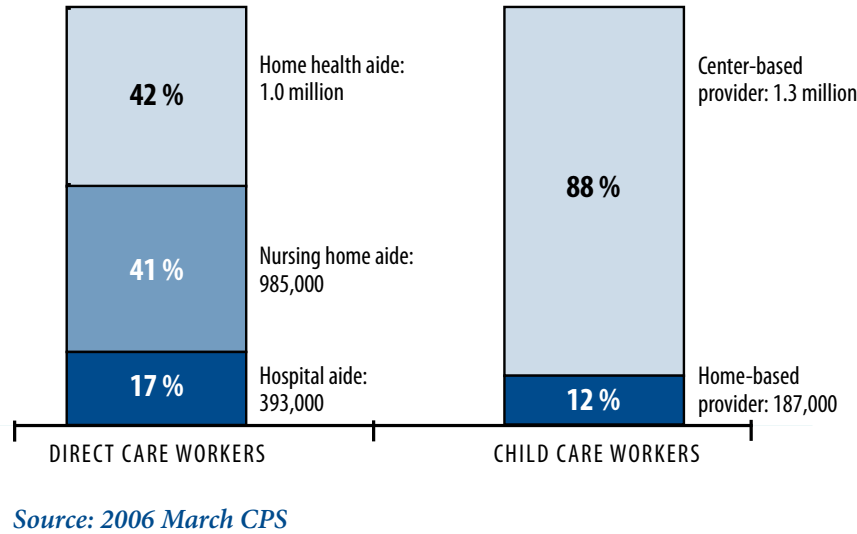


Table 2. Demographic Characteristics of Female Direct Care and Child Care Workforce, 2005

\begin{tabular}{lccc}
\hline & $\begin{array}{c}\text { All female } \\
\text { workers }\end{array}$ & $\begin{array}{c}\text { Direct care } \\
\text { workers }\end{array}$ & $\begin{array}{c}\text { Child care } \\
\text { workers }\end{array}$ \\
\hline $\begin{array}{l}\text { Race and ethnicity } \\
\text { White, non-Hispanic }\end{array}$ & 70 & 51 & 63 \\
Black, non-Hispanic & 13 & 30 & 15 \\
Other, non-Hispanic & 6 & 5 & 6 \\
Hispanic & 11 & 15 & 16 \\
\hline Foreign born & 13 & 20 & 16 \\
\hline Marital status & & & \\
Married & 54 & 38 & 49 \\
Previously married & 21 & 31 & 18 \\
Never married & 25 & 31 & 33 \\
\hline Children under 18 years & 41 & 43 & 17 \\
\hline Single mother & 14 & 24 & 38 \\
\hline Average age & 42 & 41 & 14 \\
\hline Rural residence & 15 & 20 & 1,115 \\
\hline Sample size & 48,708 & 1,696 & \\
\hline Source: 2006 March CPS & &
\end{tabular}

direct care workers are single mothers, while only 17 percent of child care providers and 14 percent of all female workers are single mothers. Nursing home aides are more likely to have children than home health or hospital aides (50 percent, 40 percent, and 32 percent, respectively) and have a higher likelihood of being a single mother. Nearly half of center child care providers have children, and marriage rates are also high among this group of workers, while home child care providers are likely to have never married, nor to have children. These differences in marital status and parenthood status leave direct care workers more vulnerable to economic stress than child care workers as the direct care workers' paycheck is more often the sole support for a family with children.

\section{Child Care Workers More Highly Educated than Direct Care Workers}

Close to two-thirds of direct care workers have only attained a high school degree or less, while less than half of child care workers have these low levels of education (see Table 3). About one-quarter of direct care workers have continued their education past high school and acquired some college education. ${ }^{12}$ Very few direct care workers have attained an associate's degree ( 9 percent) or a bachelor's degree or higher (6 percent). However, child care workers appear to be a diverse group in terms of skill, with 27 percent having some college education, 12 percent achieving an associate's degree, and 19 percent having a bachelor's degree or higher.

Direct care and child care workers have similar work hours, with 69 percent of both groups working full-time (35 hours per week or more), which is lower than all female workers (75 percent work full time). Hospital aides and nursing home aides are more likely to be employed full-time (73 percent and 77 percent, respectively) than home health aides (63 percent). Similarly, child care providers working in a home setting are less likely to work full-time than centerbased child care providers (59 percent compared with 70 percent).

\section{Direct Care Workers Have Higher Median Hourly Wages, Yet Are More Likely to be Living in Low-Income Families}

Despite larger investments in education on the part of child care providers, direct care workers median hourly wages are higher than child care workers $(\$ 9.26$ and $\$ 7.69$, respectively), although both care work occupations earn substantially less than all female workers $(\$ 13.46) \cdot{ }^{13}$ Variation exists between the direct care occupation groups-hospital aides

Table 3. Economic Characteristics of Female Direct Care and Child Care Workforce, 2005

\begin{tabular}{lccc}
\hline & $\begin{array}{c}\text { All female } \\
\text { workers }\end{array}$ & $\begin{array}{c}\text { Direct care } \\
\text { workers }\end{array}$ & $\begin{array}{c}\text { Child care } \\
\text { workers }\end{array}$ \\
\hline Education level & 37 & 62 & 42 \\
High school or less & 22 & 23 & 27 \\
Some college, no degree & 11 & 9 & 12 \\
Associate's degree & 31 & 6 & 19 \\
Bachelor's degree or higher & 37 & 37 & 36 \\
\hline Average hours per week & 75 & 69 & 69 \\
\hline Percent full-time (35 or more hours) & 46 & 44 & 44 \\
\hline Average number of & $\$ 30,441$ & $\$ 17,228$ & $\$ 15,125$ \\
\hline weeks worked per year & $\$ 18.58$ & $\$ 14.56$ & $\$ 9.89$ \\
\hline Average annual earnings & $\$ 13.46$ & $\$ 9.26$ & $\$ 7.69$ \\
\hline Average hourly earnings ${ }^{1}$ & $\$ 74,385$ & $\$ 40,445$ & $\$ 56,203$ \\
\hline Median hourly earnings & & & \\
\hline Average total family income & 8 & 19 & 15 \\
\hline Percent in poverty & 22 & 49 & 36 \\
\hline Percent low-income family ${ }^{2}$ & &
\end{tabular}

Source: 2006 March CPS

Percentages based on weighted data for female workers 19 years and older. ${ }^{1}$ Hourly wages are calculated using total annual earnings in 2005 divided by annual hours worked in 2005.

${ }^{2}$ Low-income families are those living below 200 percent of the federal poverty level. 
Figure 2. Median Hourly Wages of Female Direct Care and Child Care Workers, 2005

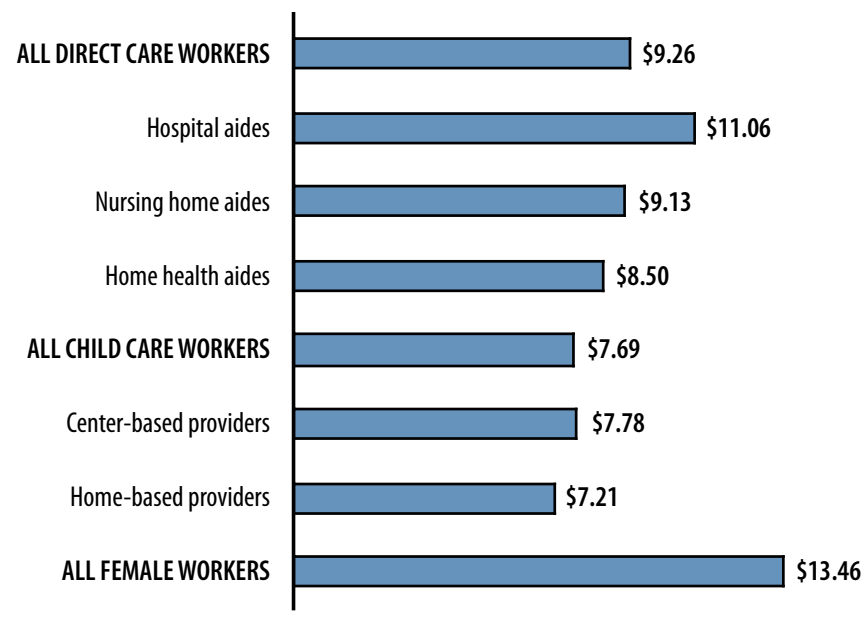

Source: 2006 March CPS

Hourly wage calculated for workers age 19 and older with positive earnings.

have the highest median hourly wages $(\$ 11.06)$, followed by nursing home aides (\$9.13) and home health aides (\$8.50). Center child care providers and home child care providers have similar median hourly wages (\$7.78 and \$7.21, respectively) (see Figure 2).

Although direct care workers earn more per hour than child care workers, they have lower total family income. On average, direct care workers' total family income in 2005 was $\$ 40,445$, while child care workers' total family income was $\$ 56,203$. The lower total family income among direct care workers is due to their lower average other family income, comprised mostly of spouses earnings but also includes assets. Recall that direct care workers are less likely to be married than child care workers, thus they are more often the sole economic providers for their families. Despite their work effort, nearly one fifth of all female direct care workers live in poverty and nearly half live in low-income families (below 200 percent of federal poverty line). Although still a sizable proportion, fewer child care workers (36 percent) live in low-income families, and only 22 percent of all female workers live in low-income families.

Direct care workers are also more likely to be minorities. Black, Hispanic, and other minority men's wages are typically lower than white men's wages. Thus, even among married direct care workers, their average total family income is likely lower than child care workers because of the higher proportion of minorities working in the direct care workforce, given that these women are likely to be married to lower earning minority men.
One Quarter of Direct Care and Child Care Workers Uninsured

In 2005, 60 percent of direct care workers had health insurance through the private sector (that is, through their employer, their spouses' employer, or purchased though a private health insurance company), and 38 percent of all direct care workers received health insurance through their employer (see Table 4). Twenty-two percent of direct care workers relied on public health insurance (primarily through Medicaid or Medicare). Fully 25 percent of direct care workers had no health insurance coverage in 2005.

Wide variation in health insurance coverage exists depending on the direct care workers' work setting. Hospital aides have the highest rates of private health insurance coverage (84 percent) and nearly two-thirds receive health insurance through their employer (63 percent). A small proportion relies on public health insurance (10 percent) and only 13 percent are uninsured. Approximately two thirds of nursing home aides receive their health insurance through a private sector source (63 percent) and 44 percent receive health insurance through their employer. Nineteen percent of nursing home aides rely on public health insurance, and 24 percent are uninsured. Home health aides, on the other hand, have the lowest level of private health insurance coverage (49 percent) and only 23 percent receive coverage through their employer. Use of public sector health insur-

Table 4. Health Insurance Coverage for Direct Care ANd Child CARE Workers, 2005

\begin{tabular}{lccccc}
\hline & \multicolumn{2}{c}{ Private sector insurance $^{1}$} & & \\
\cline { 2 - 4 } & $\begin{array}{c}\text { All private sector } \\
\text { insurance }\end{array}$ & $\begin{array}{c}\text { Employer health } \\
\text { insurance }\end{array}$ & $\begin{array}{c}\text { Public sector } \\
\text { insurance }^{2}\end{array}$ & $\begin{array}{c}\text { No } \\
\text { insurance }\end{array}$ \\
\hline All female workers & 78 & 51 & 12 & 16 \\
\hline All direct care workers & 60 & 38 & 22 & 25 \\
Hospital aides & 84 & 63 & 10 & 13 \\
Nursing home aides & 63 & 44 & 19 & 24 \\
Home health aides & 49 & 23 & 29 & 30 \\
\hline All child care workers & 61 & 20 & 18 & 27 \\
Center-based providers & 62 & 21 & 18 & 27 \\
Home-based providers & 53 & 12 & 20 & 33 \\
\hline
\end{tabular}

Source: 2006 March CPS

May total to more than $100 \%$ because some workers are covered by more than one type of health insurance.

${ }^{1}$ Private sector insurance includes insurance through an employer or union, or purchased directly from an insurance company.

${ }^{2}$ Public sector insurance includes insurance through Medicare, Medicaid, including state plans, military health care, and Indian Health Services. 
ance is relatively high among home health aides (29 percent), but even so, nearly one-third of home health aides have no health insurance.

The story is similar for child care workers, except child care workers have lower rates of employer health insurance than direct care workers, suggesting that child care workers rely to a greater extent on other private insurance, through their husband's employer for example, than direct care workers. Compared with all female workers, both direct care and child care workers are more likely to be uninsured or use public health insurance and less likely to have private sector health insurance. This disparity likely signals differences in employer provision of health insurance coverage and indicates that public insurance is not making up the gap for direct care and child care workers. Often, health insurance coverage is only offered to full-time employees and home health aides and home-based child care providers are less likely to work full-time hours. In addition, direct care and child care workers may not utilize employer health insurance when offered due to their inability to afford the premium.

\section{Direct Care and Child Care Turnover}

\section{High Turnover in Caregiving Workforce Problematic in Delivery of Quality Care}

Turnover impedes the provision of quality care in both the direct care and child care industries. Nursing homes, other long-term care providers, and state governments say that turnover and vacancies among the direct care workforce is a problem. In a recent national survey, 37 of 43 states reported serious shortages of direct care workers. ${ }^{14}$ Additionally, state-level and employer-based studies of turnover among direct care workers report annual rates that range from 25 percent to well over 100 percent. ${ }^{15}$ High rates of turnover have negative ramifications for the consumers, employers, and workers. High levels of direct care worker turnover have been shown to adversely affect patient outcomes in nursing home settings ${ }^{16}$ and lead to inadequate and unsafe care, poorer quality of life, and reduced access to services. ${ }^{17}$ Staff vacancies in the direct care field are associated with a higher risk of medical, physical, and social problems among clients and inconsistent care can negatively affect patients' quality of life and increase their likelihood of health problems. ${ }^{18}$ Turnover is costly to employers as well, with the cost of separation, vacancy, replacement, training, and increased worker injuries estimated to be at least $\$ 2,500$ per separated employee. ${ }^{19}$ Workers are adversely affected by high turnover through increased workloads and increased risk of injury, and more stress and frustration. ${ }^{20}$
Similarly, high turnover among the child care workforce is problematic. Research shows that turnover rates among the child care workforce range between 27 and 39 percent annually. ${ }^{21}$ Shortages in the elementary schools fuel turnover among the most highly qualified child care workers as teaching jobs offer better pay, benefits and job conditions. High turnover among child care providers contributes to lowerquality care, leading to unfavorable outcomes among children, such as lower language and social development. ${ }^{22}$ Child care providers play an important role in promoting child development, especially for preschoolers, whose early life experiences play a critical role in their development. High quality child care enhances early brain development, cognitive and language development, school readiness, and sets the stage for successful early school achievement. ${ }^{23}$ Therefore, understanding the factors that prevent turnover among direct care and child care workers can lead to improvements in the quality of care that the elderly and children receive.

\section{Direct Care and Child Care Occupation Retention}

Job turnover has been noted as a major and costly problem in the direct-care and child care industry. ${ }^{24}$ Turnover is costly for the employer who must recruit and train a replacement worker, and in the case of paid caregivers, it causes discontinuity in care for the elderly or children receiving that workers' care. However, many times an employee leaves her employer, switching to another employer, but remains in the same occupation. Using an individual matched file from the 2005 and 2006 CPS, we present a measure of occupation retention, defined as direct care or child care workers who remain in the same occupation one year later (from the spring of 2005 to the spring of 2006).

Among women employed in the direct care workforce in 2005, 60 percent remained in the direct care occupation a year later in 2006, while 33 percent left the field to work in another occupation and 7 percent left the labor force altogether. ${ }^{25} \mathrm{~A}$ similar proportion, 65 percent, of child care workers were still employed as child care workers one year later, in 2006.

Because characteristics predicting whether a woman will remain working in the care giving occupations are closely related to each other-for example, lower educated women also tend to have lower earnings-a multivariate regression analysis was used to ascertain the independent effects of each of the listed characteristics on the likelihood of remaining in the care giving profession one year later (from 2005 to 2006), statistically controlling for each of the other factors. The odds ratios are presented to indicate the relationship between the characteristic and the likelihood of remaining in the care giving profession (either direct care worker profession or child care worker profession separately) relative to a woman in the reference category. An odds ratio of 1.0 


\title{
Direct Care and Child Care Workers in Rural America
}

\author{
Direct Care Workers Disproportionately Reside in Rural America
}

$\mathrm{D}$ rect care workers are more likely to live in a nonmetropolitan, or rural area (20 percent) than child care workers (14 percent) and all female workers (15 percent). Nursing home aides have the highest prevalence of rural residence at 22 percent, followed by 19 percent of home health aides, and 17 percent of hospital aides. Only 8 percent of home-based child care providers reside in rural areas, while 15 percent of center-based child care providers reside in rural areas. The lower fraction of hospital aides and home-based child care providers relative to the other types of direct care and child care workers in rural areas may reflect the constrained choice available to rural residents when choosing care for the elderly or children, since hospital and nursing homes are more likely to be located in metropolitan areas. It may also reflect increased demand for home-based care in rural settings, where nursing home placement would move the elderly farther away from their homes and families. In 2005, 478,000 direct care and 212,000 child care workers lived in nonmetropolitan, or rural areas, while 1.9 million direct care and 1.2 million child care workers lived in metropolitan, or urban, areas. ${ }^{26}$

The rural direct care and child care workforce are more likely to be white, non-Hispanic than the urban caregiving workforce (see Table 5). While 72 percent of rural direct care workers and 88 percent of rural child care workers are white, non-Hispanic, only 45 percent of urban direct care workers and 59 percent of urban child care workers are. One-third of urban direct care workers are black, non-Hispanic and 17 percent are Hispanic. Very few rural direct care or child care workers are foreign born. The high proportion of minority direct care workers, and specifically black direct care workers discussed above, appears to be driven by the high proportion of urban minorities who work in the direct care profession.

Rural direct care and child care workers are more likely to be married than their urban counterparts, but rural child care workers have by far the highest marriage rates (63 percent). About 45 percent of both rural and urban direct care and child care workers have children, but direct care workers (both rural and urban are equal at 24 percent) are more likely to be single mothers than urban child care workers (18 percent) or rural child care workers (10 percent).

Rural and urban direct care workers have similar education levels, however urban child care workers are more highly educated than rural child care workers. Even so, rural child care workers are more highly educated than either the rural or urban direct care workforce. The percent of direct care and child care workers working full-time is the same regardless of rural or urban residence. Health insurance coverage is similar regardless of rural or urban residence for direct care and child care workers, with one exception-rural child care workers rely on public sector health insurance to a greater extent than their urban counterparts.

Rural direct care and child care workers have lower hourly wages than their urban counterparts and child care workers earn less than direct care workers regardless of residence. The median hourly wages of rural child care workers is $\$ 6.59$, while urban child care workers earn $\$ 8.17$ per hour. Likewise, the median hourly wages of rural direct care workers is $\$ 8.65$, and urban direct care workers earn $\$ 9.62$ per hour. However, rural direct care workers have the lowest average total family income $(\$ 35,115)$, and urban and rural child care workers have the highest total family income $(\$ 56,664$ and $\$ 54,122$, respectively). Despite their very low median hourly wages, rural child care workers have higher total family income than either of the rural or urban direct care workers, and are the least likely group to live in poverty, reflecting their high marriage rates and low likelihood of being a single mother. Regardless of rural or urban residence, one-fifth of direct care workers lived in poverty in 2005 and one half lived in low-income families.

TABle 5. CharaCteristics OF RURAL ANd URban Direct Care and Child Care Workers, 2005

\begin{tabular}{|c|c|c|c|c|}
\hline & \multicolumn{2}{|c|}{ Direct Care Workers } & \multicolumn{2}{|c|}{ Child Care Workers } \\
\hline & Rural & Urban & Rural & Urban \\
\hline \multicolumn{5}{|l|}{ Race and ethnicity } \\
\hline White, non-Hispanic & 72 & 45 & 88 & 59 \\
\hline Black, non-Hispanic & 18 & 32 & 6 & 17 \\
\hline Other, non-Hispanic & 3 & 6 & 3 & 6 \\
\hline Hispanic & 7 & 17 & 3 & 18 \\
\hline Foreign born & 3 & 24 & 1 & 19 \\
\hline \multicolumn{5}{|l|}{ Marital status } \\
\hline Married & 43 & 37 & 63 & 46 \\
\hline Previously married & 32 & 31 & 12 & 19 \\
\hline Never married & 25 & 32 & 25 & 35 \\
\hline Children under 18 years & 45 & 42 & 44 & 47 \\
\hline Single mother & 24 & 24 & 10 & 18 \\
\hline Average age & 41 & 41 & 41 & 38 \\
\hline \multicolumn{5}{|l|}{ Education level } \\
\hline High school or less & 65 & 61 & 48 & 41 \\
\hline Some college, no degree & 23 & 23 & 30 & 27 \\
\hline Associate's degree & 9 & 9 & 8 & 12 \\
\hline Bachelor's degree or higher & 3 & 7 & 14 & 20 \\
\hline Average hours per week & 37 & 36 & 36 & 37 \\
\hline Percent full-time (35 or more hours) & 69 & 69 & 65 & 69 \\
\hline \multicolumn{5}{|l|}{ Health insurance coverage } \\
\hline Private health insurance & 60 & 60 & 62 & 61 \\
\hline Employer health insurance & 39 & 38 & 15 & 21 \\
\hline Public health insurance & 25 & 21 & 24 & 17 \\
\hline No insurance & 24 & 25 & 23 & 28 \\
\hline Average annual earnings & $\$ 15,068$ & $\$ 17,775$ & $\$ 11,994$ & $\$ 15,683$ \\
\hline Average hourly earnings $^{1}$ & $\$ 10.72$ & $\$ 15.59$ & $\$ 9.60$ & $\$ 9.98$ \\
\hline Median hourly earnings $^{1}$ & $\$ 8.65$ & $\$ 9.62$ & $\$ 6.59$ & $\$ 8.17$ \\
\hline Average total family income & $\$ 35,115$ & $\$ 41,839$ & $\$ 54,122$ & $\$ 56,664$ \\
\hline Percent in poverty & 18 & 20 & 8 & 16 \\
\hline Percent low-income family ${ }^{2}$ & 50 & 48 & 37 & 36 \\
\hline
\end{tabular}

Source: 2006 March CPS

Percentages based on weighted data for female workers 19 years and older.

${ }^{1}$ Hourly wages are calculated using total annual earnings in 2005 divided

by annual hours worked in 2005.

${ }^{2}$ Low-income families are those living below 200 percent of the federal poverty level. 
indicates that a woman with this characteristic is as likely to remain in the occupation one year later as a woman with the specified reference or comparison characteristic. Ratios under 1.0 (over 1.0) indicate that a woman is less (more) likely to remain in the occupation.

\section{Higher Wages Increase Retention of Direct Care Workers}

Hospital and nursing home aides are more likely to remain in the direct care occupation than home health aides (see Table 6). The odds that hospital aides remain in the direct care occupation are 2.4 times greater than the odds that home health aides remain in the direct care occupation. Nursing home aides also have higher odds of remaining in the direct care occupation than home health aides (1.7 times more likely).

Higher annual earnings increase the likelihood of remaining in the direct care occupation. As annual earnings rise, the odds of remaining in the direct care occupation increase by 21 percent, after statistically controlling for the effects of other factors.

Likewise, direct care workers with children under 18 are more likely to remain in the direct care workforce. Hispanic women are 1.7 times as likely as white, non-Hispanic women to remain in the direct care workforce over the 1-year period. Older direct care workers are more likely to remain in the direct care workforce.

\section{Longer Work Hours Increase Retention of Child Care Workers}

The number of hours worked is significantly associated with whether a child care worker remains in the child care workforce one year later. After controlling for the other factors in the statistical model, the odds of remaining in the child care workforce increase by 2 percent with every additional hour worked per week.

Race and ethnicity are significantly associated with whether a child care worker remains in the child care workforce, with white, non-Hispanic women being more likely to remain than Hispanic and other, non-Hispanic women. Similar to direct care workers, having a child under 18 increases the odds of remaining in the child care workforce, as does age.
Table 6. Logistic Regression Predicting Odds of Remaining in Direct Care or Child Care WORKFORCE

\begin{tabular}{|c|c|c|}
\hline & $\begin{array}{l}\text { Direct Care Workers } \\
\text { Remain in Direct Care } \\
\text { Occupation in } 2006\end{array}$ & $\begin{array}{l}\text { Child Care Workers } \\
\text { Remain in Child Care } \\
\text { Occupation in } 2006\end{array}$ \\
\hline & Odds Ratio & Odds Ratio \\
\hline \multicolumn{3}{|l|}{ Direct care worker } \\
\hline Hospital aide & $2.39^{*}$ & NA \\
\hline Nursing home aide & $1.65^{*}$ & NA \\
\hline Home health aide & 1.00 & NA \\
\hline \multicolumn{3}{|l|}{ Child care worker } \\
\hline Center-based provider & NA & 1.20 \\
\hline Home-based provider & NA & 1.00 \\
\hline Annual personal earnings $(\log )$ & $1.21^{*}$ & 1.08 \\
\hline Hours worked per week & 0.99 & $1.02^{*}$ \\
\hline Employer health insurance & 0.88 & 0.74 \\
\hline Any college & 0.74 & 1.37 \\
\hline Married & 0.99 & 1.34 \\
\hline Children under 18 years & $1.63^{*}$ & $1.68^{*}$ \\
\hline \multicolumn{3}{|l|}{ Race and ethnicity } \\
\hline White, non-Hispanic & 1.00 & 1.00 \\
\hline Black, non-Hispanic & 1.19 & 0.56 \\
\hline Other, non-Hispanic & 0.58 & $0.42^{*}$ \\
\hline Hispanic & $1.71^{*}$ & $0.97^{*}$ \\
\hline Age & $1.02^{*}$ & $1.02^{*}$ \\
\hline Sample size & 482 & 356 \\
\hline chi-square & 41.9 & 34.3 \\
\hline degrees of freedom & 12 & 11 \\
\hline
\end{tabular}

Source: Individual-Matched 2005-2006 March CPS

* Significant at the 90-percent confidence level.

NA Not applicable.

Based on unweighted data for workers 19 years and older surveyed in both 2005 and 2006. 


\section{Discussion: Policies to Increase Wages}

Research links high turnover in both the direct care and child care workforce to lower-quality services and care and to negative effects on children and the elderly. Improving the quality of these paid care giving positions, through increased wages, benefits and working conditions is key to recruiting and maintaining a quality direct care and child care workforce. ${ }^{27}$ Our findings show that direct care workers with higher wages are more likely to remain in the direct care workforce one year later. The recently passed legislation to raise the federal minimum wage from $\$ 5.15$ per hour to $\$ 7.25$ per hour will effectively increase the wages of many paid caregivers-32 percent of direct care workers' and 46 percent of child care workers' wages will increase by a hike in the minimum wage (see Figure 3). In 2005, 12 percent of direct care workers and 28 percent of child care workers were paid an hourly rate of $\$ 5.15$ or lower. Another 20 percent of direct care workers and 18 percent of child care workers earned between $\$ 5.16$ and $\$ 7.25$ per hour. Some states have legislation that sets their minimum wage higher than the federal minimum wage, ${ }^{28}$ and it is also possible for states to establish a wage floor for a specific occupation through legislation.

A second policy geared toward raising the wages of direct care workers is currently being implemented in many states. Medicaid is the primary payer for long term care in the United States and contributes more than half of the direct care worker reimbursement funds. Twenty-three states are experimenting with raising the reimbursement rates via "wage pass-through" provisions in their Medicaid programs targeted at direct care workers. States have structured their pass-through provisions in a variety of ways, but regardless of the structure, the intent is to increase the labor supply of direct care workers, with the particular aim of decreasing turnover.

As many of these policies have only recently been implemented, it is not clear whether or not they have achieved the intended effect. ${ }^{29}$ However, there is some evidence that wage pass-through provisions are ineffective for a number of reasons, including: the amounts may be too small to make a difference; they are an unreliable source of funding as they are not automatic from year to year; they usually target one industry of the direct care workforce (nursing homes); and some states fail to monitor that the pass-through actually is distributed to the worker through increased wages or benefits. $^{30}$

Other strategies advanced by states, localities and advocates to improve direct care wages and benefits include linking rate increases to provider performance goals and targets; collective bargaining by direct care workers; and pursuing living wage advances, minimum wage improvements, and health insurance initiatives targeted at direct care workers. ${ }^{31}$

Several states have initiatives to build a more skilled and stable child care workforce. ${ }^{32}$ One strategy used to simultaneously increase wages for child care providers and improve quality of child care services is a tiered reimbursement rate system, with higher reimbursement rates for child care centers with higher credentials and more highly educated staff, and offering rewards to those centers with the greatest improvements in measures of quality. Another initiative uses professional development stipends for child care providers who meet certain educational and training qualifications.

Figure 3. Distribution of Direct Care and Child Care Workers by Minimum Wage Categories, 2005

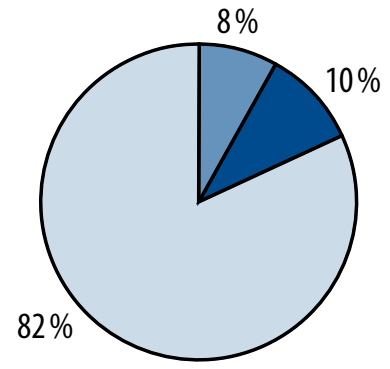

All female workers

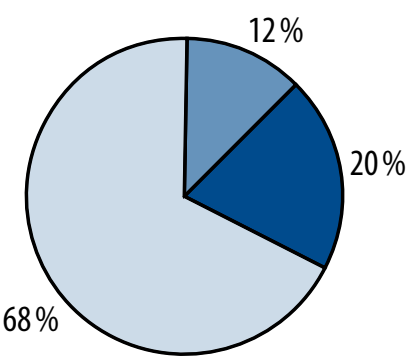

Direct care workers

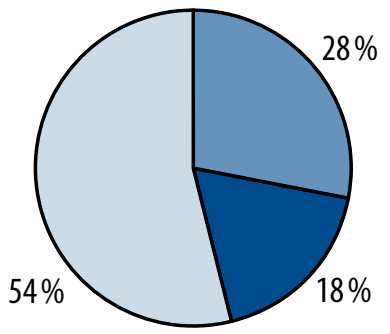

Child care workers 


\section{Conclusions}

One in every two direct care workers and one in every three child care workers live in a low-income family (below 200 percent of the poverty line), and many live in poverty. Hourly wages for the caregiving workforce are low and many lack health insurance. Despite work, these families struggle to make ends meet. Our society depends on the care work of many paid professionals-direct care and child care workers-to help meet the daily needs of our children and the elderly. To stem turnover and provide quality services to young children and the elderly, job conditions among the direct care and child care workforce must improve, and increasing wages is a promising place to start.

\section{Data used in this policy brief}

Analyses presented in this policy brief rely on data from the U.S. Census Bureau's 2006 Annual Social and Economic Surveys (ASEC) of the Current Population Survey (CPS). The CPS provides a nationally representative sample of households and the individuals in those households, and collects demographic, economic, and employment information. The CPS is a widely used source of data on labor force issues in the United States, and provides official government statistics on employment, poverty, and health insurance coverage. Demographic information refers to respondents' characteristics in the year of the survey (2006), while employment and income information refer to the preceding year (2005).

The direct care and child care workforce is identified based on both occupation and industry variables in the CPS for the longest job held in the previous year, or in 2005, following methodologies used in previous research. ${ }^{33} \mathrm{By}$ including both occupation and industry in the definition we can exclude occupations or industries that are not generally considered part of the direct care or child care workforce (such as health aides that work in manufacturing plants). Specifically, the direct care occupation codes included are personal and home care aides (3600) and nursing, psychiatric, and home health aides (4610). Direct care industries include private households (9290), hospitals (8190), nursing care facilities (8270), residential care facilities, without nursing (8290), outpatient care centers (8090), home health care services (8170), individual and family services (8370), and other health care services (8180). This yields a sample size of 1,696 female direct care workers 19 years old and over: 278 hospital aides, 703 nursing home aides, and 715 home health aides. With regard to the child care workforce, the child care occupation codes included are preschool teachers (2300) and child care workers (4600), and child care industries include private households (9290) and child day care services (8470), which yields a sample size of 1,115 female child care workers 19 years old and over: 989 center-base child care providers and 126 home-based child care providers.

The analysis of one-year workforce retention rates is based on an individual matched file created from the 2005 and 2006 CPS files. Households participate in the CPS on a rotating basis. Each household is interviewed for four consecutive months and then reinterviewed for four additional months one year later. Therefore, roughly 40 percent of the households interviewed in the spring of 2005 were also interviewed one year later, in the spring of 2006. Because of sample attrition due to geographic mobility, interviewer error, processing problems linking the same individuals across the two surveys, and response error, our individual linked file represents approximately 32 percent of the original 2005 sample (yields a sample size of 482 direct care and 356 child care workers). The linked file has several advantages that recommend its use, including its large sample size that allows for subgroup analysis like the present study, conventional information on employment status and earnings, occupation and industry, and demographics, and clearly defined beginning and end points for measuring transitions.

Comparisons presented in the text are statistically significant at the 0.10 level. See the shadow box at the front of this brief for definitions of the direct care and child care workforce. The term "rural" here refers to persons living outside the officially designated metropolitan areas. "Urban" refers to person living within metropolitan areas. For more information on official definitions, see Office of Management and Budget, OMB Bulletin No. 60-01 (December 5, 2005), available at http://www.whitehouse.gov/omb/bulletins/ fy2006/b06-01_rev_2.pdf. 


\section{Endnotes}

${ }^{1}$ England, P., M. Budig, and N. Folbre. 2002. "Wages of Virtue: The Relative Pay of Care Work." Social Problems. 49(4): 455-473.

${ }^{2}$ Wright, B. 2005. "Direct Care Workers in Long-Term Care.” Washington, DC: AARP Public Policy Institute.

${ }^{3}$ U.S. Census Bureau projections. “Table 2a. Projected Population of the United States by Age and Sex: 2000 to 2050". Accessed online at http://www.census.gov/ipc/usinterimproj/ natprojtab02a.pdf on January 3, 2007.

${ }^{4}$ U.S. Congress, Committee on Ways and Means. 2004. The Green Book. Government Printing Office: Washington, D.C.

${ }^{5}$ Paraprofessional Healthcare Institute (PHI) and North Carolina Department of Health and Human Services (NCDHHS). 2004. "Results of the 2003 National Survey of State Initiatives on the Long-term Care Direct-Care Workforce." New York: Paraprofessional Health Care Institute.

${ }^{6}$ U.S. Bureau of Labor Statistics (BLS). 2005. “Occupational Employment Statistics May 2005.” Washington, DC: U.S. Bureau of Labor Statistics.

${ }^{7}$ Hecker, D. 2004. "Occupational Employment Projections to 2012." Monthly Labor Review. Washington, DC: U.S. Bureau of Labor Statistics.

${ }^{8}$ U.S. Census Bureau projections. “Table 2a. Projected Population of the United States by Age and Sex: 2000 to 2050". Accessed online at http://www.census.gov/ipc/usinterimproj/ natprojtab02a.pdf on January 3, 2007.

${ }^{9}$ U.S. Bureau of Labor Statistics, U.S. Department of Labor, Occupational Outlook Handbook, 2006-07 Edition, Child Care Workers, Accessed online at http://www.bls.gov/oco/ ocos170.htm on May 07, 2007.

${ }^{10}$ Researchers estimate the child care workforce to be approximately 2 million, when including child care teachers, teacher's assistants, and child care workers. It is suspected that home-based child care providers are undercounted by the CPS, due to the reluctance of some workers to declare their occupation if they are concerned about unreported income, or if they do not define their child care services as an occupation, as in the case of relatives caring for children. The figures presented in this policy brief likely underrepresent the number of paid relatives, nannies, and other paid non-relatives (such as friends, neighbors, and licensed and unlicensed family child care providers) caring for children. See Burton, A., M. Whitebook, M. Young, D. Bellm, C. Wayne, R. Brandon, and E. Maher. 2002. "Estimating the Size and Components of the U.S. Child Care Workforce and Caregiving Population.” Washington, DC: Center for Child
Care Workforce, and Seattle, WA: Human Services and Policy Center.

${ }^{11}$ The remainder of this brief describes the female direct care and child care workforce 19 years old or older.

${ }^{12}$ The federal government requires that Certified Nursing Assistants (CNAs) have a minimum of 75 hours of training, and this training is provided at community colleges and trade schools, as well as by certain employers and nonprofit agencies. Less training or no training is required for Licensed Nursing Assistants (LNAs), home health aides, personal care assistants, etc.

${ }^{13}$ A median wage means that 50 percent of the workers in the occupation earn wages below this figure, and 50 percent earn wages above it. Hourly wages are calculated using the total annual earnings in 2005 divided by the annual hours worked in 2005.

${ }^{14}$ Of the 478,000 rural direct care workers, 67,000 (14\%) are hospital aides, 218,000 (46\%) are nursing home aides, and 193,000 (40\%) are home health aides. Of the 212,000 rural child care workers, 198,000 (93\%) are center-based child care providers and 14,000 (7\%) are home-based child care providers. Of the 1.9 million urban direct care workers, $326,000(17 \%)$ are hospital aides, 754,000 (40\%) are nursing home aides, and 812,000 (43\%) are home health aides. Of the 1.2 million urban child care workers, 1.1 million (87\%) are center-based child care providers and 173,000 (13\%) are home-based child care providers.

${ }^{15}$ Wright, 2005.

${ }^{16}$ PHI and NCDHHS. 2004.

${ }^{17}$ Barry, T., D. Brannon, and V. Mor. 2005. "Nurse Aide Empowerment Strategies and Staff Stability: Effects on Nursing Home Resident Outcomes." The Gerontologist 45: 309-317.

${ }^{18}$ Dawson, S. and R. Surpin. 2001. "Direct-Care Health Workers: The Unnecessary Crisis in Long-Term Care." New York: Paraprofessional Health Care Institute; and Super, N. 2002. "Who Will Be There To Care? The Growing Gap Between Caregiver Supply and Demand." Washington, DC: The George Washington University.

${ }^{19}$ Coleman, B. 2003. “Consumer Directed Personal Care Services for Older People in the U.S.” Washington, DC.: AARP Public Policy Institute; and Fleming, K., J. Evans, and D. Chutka. 2003. "Caregiver and Clinician Shortages in an Aging Nation. Mayo Clinic Proceedings 78: 1026-1040.

${ }^{20}$ Seavey, D. 2004. “The High Cost of Frontline Turnover in Long-Term Care.” Better Jobs, Better Care, Washington, DC: Institute for the Future of Aging Services. 
${ }^{21}$ Dawson and Surpin, 2001.

${ }^{22}$ Whitebook, M. 1999. "Child Care Workers: High Demand, Low Wages.” ANNALS, AAPSS, 563: 146-161; and Hayes, C., J. Palmer, and M. Zaslow (eds.) 1990. "Who Cares for America's Children? Child Care Policies for the 1990's". Washington, DC: National Research Council, National Academy Press.

${ }^{23}$ Whitebook, M., C. Howes, and D. Phillips. 1990. "Who Cares? Child Care Teachers and the Quality of Care in America: Final Report." Washington DC: Center for the Child Care Workforce.

${ }^{24}$ Shonkoff, J. and Phillips, D. 2000. (eds.) From Neurons to Neighborhoods: The Science of Early Childhood Development. Washington, DC: National Academy Press. Pp. 307-20.

${ }^{25}$ Seavey. 2004; and PHI and NCDHHS 2004.

${ }^{26}$ The small total sample size (482 direct care workers and 356 child care workers) who are present in both 2005 and 2006 prohibits examining those who change occupations and those who exit the labor force separately.

${ }^{27}$ Dawson and Surpin, 2001.

${ }^{28}$ The following six states have minimum wages higher than $\$ 7.25$ per hour as of January 1, 2007: California (\$7.50), Massachusetts (\$7.50), Oregon (\$7.80), Rhode Island (\$7.40), Vermont (\$7.53), and Washington (\$7.93).

${ }^{29}$ The authors investigate whether Medicaid pass-through provisions actually decrease turnover in a separate paper, Baughman, R. and K. Smith. 2006. "Reducing Direct Care Work Turnover: Do Wage Pass-Throughs Matter?”

${ }^{30}$ Seavey, D. and V. Salter. 2006. Paying for Quality Care: State and Local Strategies for Improving Wages and Benefits for Personal Care Assistants. Washington, DC: AARP.

${ }^{31}$ Seavey, D. and V. Salter. 2006.

${ }^{32}$ For a more full discussion of the state initiatives underway, see Whitebook, M. and B. Eichberg. 2001. "Finding a Better Way: Refining and Assessing Public Policies to Improve Child Care Workforce Compensation.” Washington, DC: Center for Child Care Workforce.

${ }^{33}$ Montgomery, R., L. Holley, J. Deichert, and K. Kosloski. 2005. "A Profile of Home Care Workers From the 2000 Census: How it Changes What We Know." The Gerontologist, 45(5):593-600. 


\section{A U T H O R S}

Kristin Smith is a family demographer at the Carsey Institute and Research Assistant Professor of Sociology at the University of New Hampshire. (kristin.smith@unh.edu)

Reagan Baughman is Assistant Professor of Economics at the University of New Hampshire. (reagan.baughman@unh.edu)

\section{A C K N O W L E D G E M E N T S}

The authors thank Dorie Seavey at the Paraprofessional Healthcare Institute, Ann Tickamyer at Ohio University, and William O'Hare at the Annie E. Casey Foundation for their thoughtful comments and suggestions, and are grateful for the assistance of the Carsey Institute staff, including Mil Duncan and Amy Seif.

\section{ANIVERSITY}

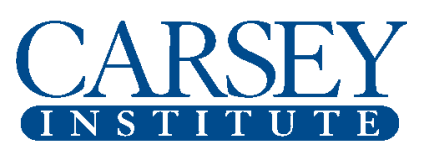

Building knowledge for families and communities in the 21st Century.

The Carsey Institute at the University of New Hampshire conducts independent, interdisciplinary research and communicates its findings to policymakers, practitioners and the general public.

Huddleston Hall

73 Main Street

Durham, NH 03824

(603) $862-2821$

www.carseyinstitute.unh.edu

The Carsey Institute Reports on Rural America are supported by the Annie E. Casey Foundation's initiative to strengthen rural families, the Ford Foundation, and by the W.K. Kellogg Foundation. 